\title{
COMUNICAÇÃO
}

\section{ESTIOLAMENTO, INCISÃO NA BASE DA ESTACA E USO DO ÁCIDO INDOLBUTÍRICO NA PROPAGAÇÃ̃O DA CARAMBOLEIRA POR ESTACAS LENHOSAS}

\author{
Effect of indolebutyric acid, etiolation and basal injury on propagation of star fruit by hardwood cuttings \\ Débora Costa Bastos ${ }^{1}$, João Alexio Scarpare Filho², Marília Neubern Libardi ${ }^{3}$, Rafael Pio ${ }^{4}$
}

\begin{abstract}
RESUMO
Objetivou-se, neste trabalho, avaliar o efeito do estiolamento, da incisão na base da estaca e do tratamento com ácido indolbutírico (AIB) no enraizamento de estacas lenhosas de caramboleira. As estacas foram padronizadas com um par de folhas inteiras e $12 \mathrm{~cm}$ de comprimento. O experimento foi conduzido em delineamento estatístico inteiramente casualizado, em arranjo fatorial 3 x 4, onde os fatores estudados foram técnicas aplicadas nas estacas (estiolamento, ferimento na base e controle) e diferentes concentrações de $\operatorname{AIB}\left(0 ; 3.000 ; 6.000\right.$ e $\left.9.000 \mathrm{mg} \mathrm{L}^{-1}\right)$. As estacas lenhosas foram utilizadas como tratamento-controle. O estiolamento foi realizado 45 dias antes da retirada da estaca no ramo, envolvendo-se a base da futura estaca com fita plástica preta. A incisão na base da estaca foi realizada no preparo das mesmas, através de dois cortes na base. As estacas foram mantidas em câmara de nebulização intermitente e, após 75 dias, avaliaram-se as porcentagens de estacas enraizadas, de estacas vivas, de formação de calos e o número de raízes emitidas por estaca. Concluiu-se que as técnicas de estiolamento e ferimento na base da estaca, e a aplicação de AIB não induziram a formação de raízes em estacas lenhosas de caramboleira.
\end{abstract}

Termos para indexação: Averrhoa carambola L., AIB, carambola, propagação e regulador de crescimento.

\begin{abstract}
The aim of this work was to verify the influence of shading, lesion in cutting bases and application of Indolbutyric acid (IBA) in the rooting of star fruit hardwood cuttings. The cuttings were padronized with three buds, two leaves, and $12 \mathrm{~cm}$ of length. The experimental design was completely randomized, with the factorial scheme $3 \times 4$, where the studied factors were the cutting types (shaded hardwood, hardwood with lesion on the base, and hardwood, considered the control) and different concentration of IBA ( 0 ; 3,$000 ; 6,000$, and $9,000 \mathrm{mg} \mathrm{L}^{-1}$ ). The shading started 45 days before removing the cuttings from the branch, wrapping up the base of the future cuttings with black plastic tape. The incision on the base of the cuttings was performed at the moment they were removed from the branch, through two cuts on the base. The cuttings were maintained in a chamber under intermittent mist and after 75 days, the rooting percentage, survival percentage, callus formation percentage and length roots per cuttings were evaluated. It was concluded that hardwood cuttings without the treatments of shading and lesion on the base and application of IBA showed the best results of rooting.
\end{abstract}

Index terms: Averrhoa carambola L., IBA, star fruit, propagation and growth regulator.

(Recebido em 23 de julho de 2007 e aprovado em 12 de fevereiro de 2008)

A caramboleira é uma planta frutífera de clima tropical, cultivada economicamente em várias partes do mundo, principalmente na região da Ásia. No Brasil, a exploração comercial ocorre principalmente no Estado de São Paulo, onde a cultura está em crescente expansão, devido às condições climáticas favoráveis, à facilidade de produção, e a comercialização em mercados consumidores internos e externos (DONADIO et al., 2001).

Os métodos mais utilizados na produção de mudas da caramboleira são as sementes para a formação de porta- enxertos e a enxertia. Embora a propagação através de estacas não seja muito utilizada na formação de mudas, constitui um método que tem sido alvo de estudos e pesquisas relacionadas, principalmente, aos tipos de estacas, à época de realização, ao uso de reguladores de crescimento, entre outros, uma vez que a estaquia é um método promissor na propagação da caramboleira (BASTOS, 2002).

Entre as principais técnicas que podem aumentar o índice de enraizamento de estacas de caramboleira, destaca-

\footnotetext{
'Engenheira Agrônoma, Doutora, Pesquisadora - Embrapa Semi-Árido - Br 428, Km 152 - Zona Rural - Cx. P. 23 - $56302-970$ - Petrolina, PE debora@cpatsa.embrapa.br, dcbfatinansi@gmail.com

2Engenheiro Agrônomo, Doutor, Professor Associado - Departamento de Produção Vegetal - Escola Superior de Agricultura "Luiz de Queiroz"/ESALQ Universidade de São Paulo/USP - Avenida Pádua Dias 11 - Cx. P. 09 - 13418-900 - Piracicaba, SP - jascarpa@esalq.usp.br

${ }^{3}$ Engenheira Agrônoma - Escola Superior de Agricultura "Luiz de Queiroz"/ESALQ - Universidade de São Paulo/USP - Avenida Pádua Dias 11 - Cx. P. 09 13418-900 - Piracicaba, SP - mnlibardi@yahoo.com.br

${ }^{4}$ Engenheiro Agrônomo, Doutor, Professor Adjunto - Universidade Estadual do Oeste do Paraná/UNIOESTE - Rua Pernambuco, 1777 - Centro - $85960-000$ -

Cx. P. 1008 - Marechal Cândido Rondon, PR - rafaelpio@hotmail.com
} 
se a utilização de reguladores de crescimento, o estiolamento dos ramos e a realização de incisões (ferimentos), na base das estacas (BASTOS, 2006). A aplicação exógena de reguladores de crescimento pode aumentar a capacidade na formação de raízes adventícias em estacas, que têm por finalidade induzir o processo rizogênico, aumentando a porcentagem de estacas que formam raízes, o número e a qualidade das raízes formadas, bem como a uniformidade no enraizamento (TOFANELLI et al., 2005). As auxinas são os reguladores de crescimento mais utilizados para favorecer o processo de formação de raízes, sendo o ácido indolbutírico (AIB) a principal auxina sintética utilizada para esse fim (MIRANDA et al., 2004). Porém ela apresenta resultados bastante variáveis conforme a espécie e/ou cultivar utilizada, tipo de estaca, época do ano, concentração, modo de aplicação, condições ambientais, entre outras (FACHINELLO et al., 1995).

Define-se como estiolamento o desenvolvimento de brotos, ramos ou partes de ramos em ausência de luz, causando crescimento geralmente alongado, de coloração amarela ou branca em razão da ausência de clorofila, consistindo assim em uma técnica que também vem sendo utilizada na melhoria do enraizamento das estacas (HARTMANN et al., 2002).

A utilização de incisões na base das estacas permite que haja o rompimento de barreira física exercida pelos anéis de esclerênquima, além do aumento da taxa respiratória e nos teores de auxina, carboidratos e etileno na área lesionada, o que pode favorecer a emissão de raízes, principalmente em estacas lenhosas (FACHINELLO et al., 1995).

Objetivou-se, aqui, o estudo do enraizamento de estacas lenhosas de caramboleiras, utilizando-se o ácido indolbutírico, o estiolamento dos ramos e incisões na base das estacas.

O experimento foi conduzido em novembro de 2002, na área de produção de mudas do Departamento de Produção Vegetal da ESALQ/USP, em Piracicaba-SP. O material propagativo foi obtido de plantas matrizes de caramboleira cultivar B-10, com 15 anos de idade, em pomares comerciais situados em Jaguariúna-SP.

No estiolamento parcial (45 dias antes da retirada da estaca), realizado no dia 04 de outubro de 2002, utilizouse fita de polietileno de cor preta $(1,5 \mathrm{~cm}$ de largura), que foi enrolada na base das brotações (ramos lenhosos), cobrindo-se aproximadamente $5 \mathrm{~cm}$ da região de uma gema e da área próxima a ela, ficando $12 \mathrm{~cm}$ abaixo do ápice. Após esse período, ou seja, no dia 19 de novembro de 2002 foram coletadas estacas com folhas, padronizadas com $12 \mathrm{~cm}$ de comprimento e 0,6 a $0,8 \mathrm{~cm}$ de diâmetro (estioladas e não- estioladas).
Parte das estacas não-estioladas sofreu incisões mecânicas na base com auxílio de um canivete. As incisões foram realizadas através de dois cortes laterais na base da estaca, com cerca de $1,0 \mathrm{~cm}$ de comprimento, nos quais se eliminou uma porção da casca com o objetivo de expor uma maior área da região cambial. Parte das estacas foi utilizada como tratamento- controle, sem estiolamento e ferimento na base.

Após o preparo das estacas, imergiu-se sua base em solução de AIB (ácido indolbutírico $-\mathrm{C}_{12} \mathrm{H}_{13} \mathrm{NO}_{2}-$ Merck S.A.), nas concentrações de 0, 3.000, 6.000 e 9.000 $\mathrm{mg} \mathrm{L}^{-1}$, durante 20 (vinte) segundos. No preparo da solução, dissolveu-se o AIB em dez gotas de hidróxido de sódio $(\mathrm{NaOH} 0,5 \mathrm{~N})$, visando facilitar a posterior homogeneização em água destilada.

A seguir, as estacas foram acondicionadas em bandejas de poliestireno expandido (isopor) de 72 células (células de formato piramidal invertida, orifício na base para escoamento de água e capacidade de $120 \mathrm{~cm}^{3}$ de substrato), preenchidas com substrato vermiculita de grânulos médios, colocando-se uma estaca por célula.

As bandejas foram acondicionadas em câmara de nebulização intermitente (temperatura de $25 \pm 5^{\circ} \mathrm{C}$, UR média de $72 \%$, tempo de aspersão de 20 segundos, em intervalos de 10 minutos). Em cada bandeja foram colocadas 3 (três) repetições, dispostas ao acaso, sendo que cada parcela foi composta por 10 estacas.

Foi utilizado o delineamento estatístico inteiramente casualizado, em arranjo fatorial $3 \times 4$, correspondendo a 12 tratamentos, onde os fatores estudados foram técnicas aplicadas nas estacas (estiolamento, ferimento - incisões na base e controle) e concentrações de $\operatorname{AIB}(0,3.000,6.000$ e $9.000 \mathrm{mg} \mathrm{L}^{-1}$ ), com 3 repetições e 10 estacas por unidade experimental, perfazendo um total de 360 estacas.

Após 75 dias, em 04 de fevereiro de 2003, avaliaramse as porcentagens de estacas enraizadas, de estacas vivas e de calos formados, além do número de raízes emitidas por estaca.

Para efeito da análise estatística, os dados em porcentagem foram transformados em arc sen $\sqrt{x+1} \mathrm{e}$ submetidos à análise de variância através do teste de Scott \& Knott (1974). As médias comparadas ao nível de 5\% de probabilidade (GOMES, 2000). As análises foram realizadas pelo programa computacional Sistema para Análise de Variância - SISVAR (FERREIRA, 2000).

Verificou-se que somente houve efeito significativo para porcentagem de estacas enraizadas (PEE) das técnicas utilizadas na caramboleira. Não foram observadas diferenças estatísticas significativas para as porcentagens de sobrevivência, formação de calos e número de raízes por estaca, entre as diferentes técnicas estudadas (Tabela 1). 
Esperava-se que a técnica utilizada de estiolamento das estacas promovesse maior enraizamento, pois, segundo Hartmann et al. (2002), as estacas estioladas têm maior capacidade de formar raízes e contêm maior teor de auxina quando comparadas às estacas não-estioladas. Entretanto, essas técnicas apresentaram resultados significativamente inferiores às estacas sem tratamento. Além do estiolamento dos ramos, outra técnica que pode favorecer a formação de raízes é o ferimento, incisão ou lesão feita na base das estacas. De acordo com Biasi et al. (2000), a atividade celular na área lesionada é estimulada pelo aumento da taxa respiratória, elevação nos teores de auxinas, carboidratos e etileno, resultando na formação de raízes nas margens da lesão. $\mathrm{O}$ ferimento na base das estacas mostrou-se benéfico para o enraizamento de diversas espécies lenhosas, por estimular a divisão celular e a formação de calos. Os resultados obtidos nesse trabalho demonstraram que o ferimento na base da estaca também prejudicou a formação de raízes (Tabela 2).

Esses resultados contrastam também com os observados por Tofanelli et al. (2005), que em estudos com estacas de pessegueiro, observaram que o maior enraizamento ( $82 \%$ ) foi obtido nas estacas onde se efetuou o ferimento. Boliani (1986), em estudos com estacas de nespereira, concluiu que o estiolamento basal não influenciou no enraizamento. Entretanto, os resultados dessa pesquisa foram semelhantes aos obtidos por Rajan \& Ram (1983) que, estudando o efeito do número de incisões juntamente com AIB no enraizamento de estacas de mangueira, concluíram que quanto mais incisões na estaca, menor o número de raízes e a porcentagem de enraizamento das mesmas.

Não houve diferença significativa da utilização de AIB nas características avaliadas nesse trabalho. Embora as auxinas sejam reguladores de crescimento que induzem à formação de raízes em estacas e, freqüentemente consideradas como limitantes do enraizamento, elas podem apresentar pouco ou nenhum efeito em espécies de difícil enraizamento (WILSON, 1994). Os resultados observados nesse trabalho discordaram de Bastos (2002) que, em estudos com estacas de caramboleira, verificou que a concentração de $5000 \mathrm{mg} \mathrm{L}^{-1}$ de AIB foi a que promoveu maior porcentagem de enraizamento $(63,5 \%)$. Sugere-se, pelos dados obtidos, que o teor de auxina endógena contido

Tabela 1 - Análise de variância das características: porcentagem de estacas enraizadas (PEE), porcentagem de estacas vivas (PEV), porcentagem de formação de calos (PFC) e número médio de raízes emitidas por estaca (NREE), em função da aplicação de diferentes técnicas e concentrações de AIB. ESALQ/USP, Piracicaba -SP, 2005.

\begin{tabular}{lccccc}
\hline \multicolumn{1}{c}{ Causas de Variação } & GL & PEE & PEV & PFC & NREE \\
\hline Técnicas Utilizadas (A) & 2 & $0,0031^{* *}$ & $0,0732^{\mathrm{NS}}$ & $0,0406^{\mathrm{NS}}$ & $0,0327^{\mathrm{NS}}$ \\
Concentrações de AIB (B) & 3 & $0,1802^{\mathrm{NS}}$ & $0,6347^{\mathrm{NS}}$ & $0,7512^{\mathrm{NS}}$ & $0,1823^{\mathrm{NS}}$ \\
A X B & 6 & $0,4908^{\mathrm{NS}}$ & $0,5537^{\mathrm{NS}}$ & $0,5886^{\mathrm{NS}}$ & $0,8836^{\mathrm{NS}}$ \\
Resíduo & 24 & - & - & - & - \\
\hline Total & 35 & - & & - & - \\
* Teste F da análise de variância. & & & & & - \\
Ns não significativo & & & &
\end{tabular}

Tabela 2 - Médias das porcentagens de estacas enraizadas (PEE), estacas vivas (PEV), formação de calo (PFC) e número médio de raízes por estaca (NREE) de caramboleira, em função das diferentes técnicas utilizadas. ESALQ/USP, Piracicaba - SP, 2005.

\begin{tabular}{lclll}
\hline \multicolumn{1}{c}{ Técnicas Utilizadas } & PEE $(\%)^{*}$ & PEV $(\%)$ & PFC $(\%)$ & NREE \\
\hline Lenhosa & $20,83 \mathrm{a}$ & $45,00 \mathrm{a}$ & $40,83 \mathrm{a}$ & $7,02 \mathrm{a}$ \\
Lenhosa Estiolada & $4,17 \mathrm{~b}$ & $25,83 \mathrm{a}$ & $19,17 \mathrm{a}$ & $2,28 \mathrm{a}$ \\
Lenhosa com Ferimento & $12,50 \mathrm{~b}$ & $29,17 \mathrm{a}$ & $31,67 \mathrm{a}$ & $4,23 \mathrm{a}$ \\
\hline cv $(\%)$ & 49,22 & 43,50 & 42,62 & 44,78 \\
\hline
\end{tabular}

*As médias seguidas de mesma letra, na coluna, não diferem entre si pelo teste de Scott-Knott, a 5\% de probabilidade. 
nas estacas (controle), possivelmente possa ter sido suficiente para promover o enraizamento, não sendo necessária a aplicação de AIB e das técnicas de estiolamento e ferimento. Entretanto, não se pode afirmar com certeza a razão do ocorrido nas estacas. Segundo Ramos et al. (2003), o fornecimento exógeno de auxina, em certas quantidades, pode promover uma alteração hormonal, favorecendo ou não o enraizamento de estacas. Para muitas espécies, têm-se observado que o enraizamento só é possível quando as estacas são submersas em reguladores de crescimento, podendo ser benéficos ou inibitórios, dependendo da concentração do mesmo (ROSA, 1993; TOFANELLI, 1999). Dessa forma, neste trabalho, com a realização do estiolamento e ferimento, técnicas que podem induzir e aumentar a formação de auxinas nas estacas, houve um efeito inibidor (Figura 1).

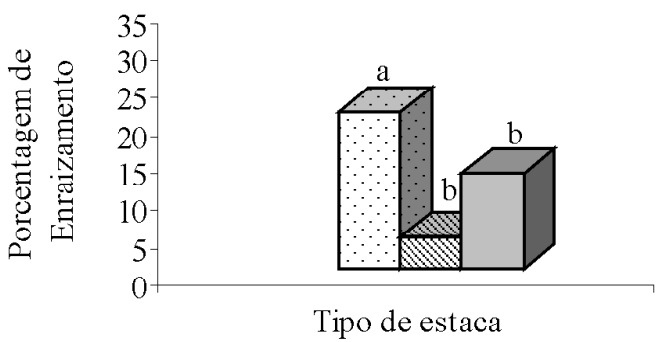

$\square$ Lenhosa \&enhosa Estiolada
$\square$ Lenhosa com Ferimento

Figura 1 - Porcentagem de enraizamento das diferentes técnicas utilizadas na caramboleira. ESALQ/USP, Piracicaba-SP, 2005.

Os trabalhos encontrados na literatura relacionados ao estudo da interação entre as técnicas utilizadas para promover o enraizamento de estacas são bastante contraditórios. Reis et al. (2000), em estudos com estacas de pereira, verificaram que a técnica de estiolamento, quando aplicada isoladamente, influencia no enraizamento e no comprimento das raízes, porém, quando aplicada juntamente com o regulador de crescimento não tem efeito nessas duas características, sendo os melhores resultados observados em estacas sem o estiolamento e o tratamento com o regulador. Souza et al. (1995), concluíram que os ferimentos na base da estaca juntamente com a aplicação de AIB, não foram suficientes para induzir o enraizamento das estacas de ameixeira cultivar Reubennel e Costa Júnior (2000) considerou desnecessária a utilização de AIB, no enraizamento de estacas estioladas de goiabeira cultivar Rica. Similarmente, Villa et al. (2003) observaram maior porcentagem de enraizamento em estacas de amoreira-preta cultivar Brazos, quando não se utilizou o AIB $(62,38 \%)$. Por outro lado, Souza et al. (1995) obtiveram 81,7\% de enraizamento em estacas de ameixeira cultivar Frontier quando elas foram lesionadas na base e $54,5 \%$, nas estacas sem lesão. Camolesi et al. (2007), em estudos com estacas semilenhosas de pessegueiro 'Okinawa' verificaram que a lesão na base proporcionou aumento da porcentagem de estacas enraizadas e do número de raízes por estaca, sendo os melhores resultados observados para as estacas que sofreram lesão e que foram tratadas com AIB, em concentrações de 1.500 e $2.000 \mathrm{mg} \mathrm{L}^{-1}$.

Para a porcentagem de estacas vivas, formação de calos e número de raízes por estaca não foram observadas diferenças significativas entre as técnicas utilizadas e a aplicação de ácido indolbutírico (Tabela 2). Verificou-se ainda que, mesmo sem haver efeito significativo da técnica utilizada e das concentrações de AIB, maiores índices de estacas vivas $(45,00 \%)$, formação de calos $(40,83 \%)$ e do número de raízes por estaca $(7,02)$ foram observados nas estacas lenhosas (controle). Esses resultados foram discordantes dos obtidos por Nachtigal (1999), em estacas de pessegueiro, que concluiu haver relação positiva entre a porcentagem de sobrevivência e de enraizamento.

Dessa forma, de acordo com os resultados obtidos pode-se concluir que:

- não houve efeito significativo da utilização do regulador de crescimento, no enraizamento de estacas lenhosas de caramboleira;

- a utilização das técnicas de estiolamento e ferimento, na base das estacas lenhosas de caramboleira, prejudicou o enraizamento das mesmas.

\section{REFERÊNCIAS BIBLIOGRÁFICAS}

BASTOS, D. C. Efeito da época de coleta, estádio do ramo e do tratamento com IBA no enraizamento de estacas de caramboleira (Averrhoa carambola L.). 2002. $75 \mathrm{f}$. Dissertação (Mestrado em Agronomia) - Universidade Estadual Paulista, Jaboticabal, 2002.

BASTOS, D. C. Propagação da caramboleira por estacas caulinares e caracterização anatômica e histológica da formação de raízes adventícias. 2006. $65 \mathrm{f}$. Tese (Doutorado em Agronomia) - Escola Superior de Agricultura "Luiz de Queiroz", Universidade de São Paulo, Piracicaba, 2006. 
BIASI, L. A.; STOLTE, R. E.; SILVA, M. F. Estaquia de ramos semilenhosos de pessegueiro e nectarina. Revista Brasileira de Fruticultura, Jaboticabal, v. 22, n. 3, p. 421425, dez. 2000.

BOLIANI, A. C. Efeitos do estiolamento basal, da juvenilidade e do uso de regulador vegetal no enraizamento de estacas de raízes e de ramos herbáceos de algumas espécies frutíferas. 1986. 129 p. Dissertação (Mestrado em Agronomia) - Escola Superior de Agricultura Luiz de Queiroz, Universidade de São Paulo, Piracicaba, 1986.

CAMOLESI, M. R.; UNEMOTO, L. K.; SACHS, P. J. D.; ROBERTO, S. R.; SATO, A. J.; FARIA, A. P.; RODRIGUES, E. B.; SILVA, J. V. Enraizamento de estacas semilenhosas de pessegueiro 'Okinawa' sob efeito de lesão e ácido indolbutírico. Ciência Rural, Santa Maria, v. 37, n. 6, p. 1805-1808, 2007.

COSTA JÚNIOR, W. H. da. Enraizamento de estacas de goiabeiras: influência de fatores fisiológicos e mesológicos. 2000. 66 f. Dissertação (Mestrado em Agronomia) - Escola Superior de Agricultura "Luiz de Queiroz”, Universidade de São Paulo, Piracicaba, 2000.

DONADIO, L. C.; SILVA, J. A. A.; ARAÚJO, P. R. S.; PRADO, R. M. Caramboleira (Averrhoa carambola L.). Jaboticabal: Sociedade Brasileira de Fruticultura, 2001. 81 p. (Série frutas potenciais).

FACHINELLO, J. C.; HOFFMANN, A.; NACHTIGAL, J. C.; KERSTEN, E.; FORTES, G. R. L.Propagação de plantas frutíferas de clima temperado. Pelotas: UFPel, 1995. 179 p.

FERREIRA, D. F. Análise estatística por meio do SISVAR (Sistema para Análise de Variância) para Windows versão 4.0. In: REUNIÃO ANUAL DA REGIÃO BRASILEIRA DA SOCIEDADE INTERNACIONAL DE BIOMETRIA, 45. 2000, São Carlos. Anais... São Carlos: UFSCar, 2000. p. 255258.

GOMES, F. P. Curso de estatística experimental. 14. ed. Piracicaba: USP/ESALQ, 2000. 477 p.

HARTMANN, H. T.; KESTER, D. E.; DAVIES JUNIOR, F. T.; GENEVE, R. L. Plant propagation: principles and pratices. 7. ed. New Jersey: Prentice-Hall, 2002. 880 p.

MIRANDA, C. S.; CHALFUN, N. N. J.; HOFFMANN, A.; DUTRA, L. F.; COELHO, G. V. A. Enxertia recíproca e AIB como fatores indutores do enraizamento de estacas lenhosas dos porta-enxertos de pessegueiro "Okinawa" e umezeiro. Ciência e Agrotecnologia, Lavras, v. 28, n. 4, p. 778-784, 2004.

NACHTIGAL, J. C. Obtenção de porta-enxertos 'Okinawa' e de mudas de pessegueiro (Prunus persica (L.) Batsch) utilizando métodos de propagação vegetativa. 1999. $165 \mathrm{f}$. Tese (Doutorado em Agronomia) - Universidade Estadual Paulista, Jaboticabal, 1999.

RAJAN, S.; RAM, S. Some factors effecting root regeneration in mango cuttings in mist and hot bed. Progressive Horticulture, Nainital, v. 15, n. 1/2, p. 11-16, 1983.

RAMOS, J. D.; MATOS, L. E. S.; GONTIJO, T. C. A.; PIO, R.; JUNQUEIRA, K. P.; SANTOS, F. C. Enraizamento de estacas herbáceas de 'Mirabolano' (Prunus cerasifera Ehrn) em diferentes substratos e concentrações de ácido indolbutírico. Revista Brasileira de Fruticultura, Jaboticabal, v. 25, n. 1, p. 189-191, 2003.

REIS, J. M. R.; CHALFUN, N. N. J.; LIMA, L. C. O.; LIMA, L. C. Efeito do estiolamento e do ácido indlobutírico no enraizamento de estacas do porta enxerto Pyrus calleryana Dene. Ciência e Agrotecnologia, Lavras, v. 24, n. 4, p. 931938, 2000 .

ROSA, L. S. Influência de diferentes concentrações de ácido indol-3-butírico e do tamanho da estaca na formação de raízes adventícias em Carapa guianensis Aubl. In: CONGRESSO FLORESTAL PANAMERICANO, 1., 1993, Curitiba. Anais... Curitiba: SBS-SBEF, 1993. v. 2, p. 432-434.

SCOTT, A. J.; KNOTT, M. A cluster analysis method for grouping means in the analysis of variance. Biometrics, Washington, v. 30, p. 507-512, Sept. 1974.

SOUZA, C. de; NACHTIGAL, J. C.; KERSTEN, E. Efeito da lesão e do ácido indolbutírico no enraizamento de duas cultivares de ameixeira (Prunus salicina, Lindl) através de estaca. Revista Brasileira de Agrociência, Pelotas, v. 1, n. 3, p. 171-174, 1995.

TOFANELLI, M. B. D. Enraizamento de estacas lenhosas e semilenhosas de cultivares de pessegueiro em diferentes concentrações de ácido indolbutírico. 1999. 87 p. Dissertação (Mestrado em Agronomia) - Universidade Federal de Lavras, Lavras, 1999. 
TOFANELLI, M. B. D.; RODRIGUES, J. D.; ONO, E. O. 2,6Di-hidroxiacetofenona e tipo de corte basal no enraizamento de estacas semilenhosas de pessegueiro 'Okinawa'. Ciência Rural, Santa Maria, v. 35, n. 2, p. 462-464, mar./abr. 2005.

VILLA, F.; PIO, R.; CHALFUN, N. N. J.; GONTIJO, T. C. A.; DUTRA, L. F. Propagação de amoreira-preta utilizando-se estacas lenhosas. Ciência e Agrotecnologia, Lavras, v. 27, n. 4, p. 829-834, jul./ago. 2003.

WILSON, P. J. The concept of a limiting rooting morphogen in woody stem cuttings. Journal of Horticultural Science, Alexandria, v. 69, n. 4, p. 591-600, 1994. 